\title{
Home advantage in the Winter Olympics (1908-1998)
}

\author{
NIGEL J. BALMER, ${ }^{1}$ ALAN M. NEVILL ${ }^{2 *}$ and A. MARK WILLIAMS ${ }^{1}$ \\ ${ }^{1}$ Research Institute for Sport and Exercise Sciences, Liverpool fohn Moores University, Webster Street, Liverpool L3 $2 E T$ \\ and ${ }^{2}$ School of Sport, Performing Arts and Leisure, University of Wolverhampton, Walsall Campus, Gorway Road, \\ Walsall WS1 3BD, UK
}

Accepted 11 October 2000

\begin{abstract}
We obtained indices of home advantage, based on the medals won by competing nations, for each event held at the Winter Olympics from 1908 to 1998. These indices were designed to assess home advantage while controlling for nation strength, changes in the number of medals on offer and the performance of 'non-hosting' nations. Some evidence of home advantage was found in figure skating, freestyle skiing, ski jumping, alpine skiing and short track speed skating. In contrast, little or no home advantage was observed in ice hockey, Nordic combined, Nordic skiing, bobsled, luge, biathlon or speed skating. When all events were combined, a significant home advantage was observed $(P=0.029)$, although no significant differences in the extent of home advantage were found between events $(P>0.05)$. When events were grouped according to whether they were subjectively assessed by judges, significantly greater home advantage was observed in the subjectively assessed events $(P=0.037)$. This was a reflection of better home performances, suggesting that judges were scoring home competitors disproportionately higher than away competitors. Familiarity with local conditions was shown to have some effect, particularly in alpine skiing, although the bobsled and luge showed little or no advantage over other events. Regression analysis showed that the number of time zones and direction of travel produced no discernible trends or differences in performance.
\end{abstract}

Keywords: familiarity, subjective judgements, travel.

\section{Introduction}

The existence of home advantage has been well documented (see Nevill and Holder, 1999, for a review); the causes, however, are not so clear. Courneya and Carron (1992) identified four factors thought to account for home advantage. These fall under the headings of crowd factors, learning or familiarity factors, travel factors and rule factors. Crowd factors have been shown to create home advantage and, more recently, to have a direct influence on officiating. Nevill et al. (1996) identified frequencies of penalties and sendings-off in association football to favour the home side. In addition, the imbalances in favour of the home side increased with crowd size. This led to the conclusion that the crowd may either influence away players to play more recklessly or affect the match officials' decisions to favour the home side. The latter of these suggestions

\footnotetext{
* Author to whom all correspondence should be addressed. e-mail: a.m.nevill@wlv.ac.uk
}

was supported experimentally by Nevill et al. (1999). Two groups, one with background crowd noise and one without, judged the legality of 52 challenges from a televised football match. Analysing the proportion of fouls awarded by the two groups as a binary response variable yielded a significant two-way interaction between 'noise group' and 'team representation'. Crowd noise appeared to influence the observers to favour the home side and penalize the away side. If crowd noise were to influence officiating in the Winter Olympics, this effect should be most significant in events relying entirely on judges for scoring, where such an influence could be most potent. In figure skating or freestyle skiing, for example, the influence of a crowd upon judges would have a direct bearing on the scores of competitors.

Familiarity with local conditions remains a largely unsubstantiated contributor to home advantage (Schwartz and Barsky, 1977; Dowie, 1982; Pollard, 1986). However, the sports examined (ice hockey, basketball, baseball, American football and association 
football) have relatively little potential for variation in local conditions, in contrast to alpine skiing for example. Clark and Norman (1995) found some evidence (although non-significant) of increased home advantage in association football using teams with an unusual pitch size or surface. This observation was supported by Barnett and Hilditch (1993), again in association football, who found increased home advantage for teams with artificial playing surfaces; such surfaces have been outlawed in the English and Scottish leagues. It is not surprising that the increased incidence of home advantage because of local conditions occurred when the difference was at its greatest (grass $v s$ artificial surfaces). It should follow that if familiarity is significant in the Winter Olympics, it should be most evident in alpine skiing, where the potential for variation is at its greatest. This was confirmed by Bray and Carron (1993), who acknowledged that the 'beneficial effects of familiarity with the venue could contribute generally and specifically to the home advantage in world cup alpine skiing'.

Whether travel affects performance has yet to be investigated thoroughly in the context of the Winter Olympics; research regarding its influence in other sports has not been conclusive. Pace and Carron (1992) proposed that 'only a small portion of the variance in the home advantage/visitor disadvantage can be explained by travel related factors'. They were, however, referring to the National Hockey League, where time-zone traversal may only vary between 0 and $3 \mathrm{~h}$. In the National Football League, there is only a limited range of time-zone traversal (Jehue et al., 1993). However, Jehue et al. found direction of travel and time of day to be important, and suggested a possible 'jet-lag' effect. For the Winter Olympics, the range of time zones traversed is far greater $(-17$ to $+16 \mathrm{~h})$, although information as to the time of day each event took place was not available. For jet-lag, with results stretching as far back as 1908, rapid traversal of time zones was evidently not possible. It was not until the advent of four-engine transports and jet airliners in 1958, when rail and ocean liners were replaced as the primary mode of longdistance travel, that jet-lag became a reality. If jet-lag is influential, then its influence should be seen after 1958 and possibly vary with magnitude and direction of travel. Given the likelihood that time would be available to overcome such adverse effects, the influence of such travel factors should be marginal.

The outcome of many Olympic events is determined using an objective and quantitative scale (e.g. time, distance) while others have relied on less clear-cut and more subjective judgements. Ansorge and Scheer (1988) suggested that the 'effects of biased officiating are potentially most dramatic in sports in which the officials actually score the points through judging the performance of athletes with some combination of objective and subjective criteria'. This would be particularly relevant to sports with a major subjective element, such as gymnastics and diving or figure skating and freestyle skiing. Previous research based on the Olympic Games has focused on the influence of officiating on political and nationalistic bias, disregarding it as a possible source of home advantage.

Previous research has consistently shown significant biased officiating. Seltzer and Glass (1991) analysed the judging of 417 skaters (and 3753 rankings) in Olympic skating events from 1968 to 1988 . They found that judges awarded significantly higher scores to participants from their own countries and that scoring was guided by 'cold war' politics. The Soviet Union, for example, directly penalized American skaters, while the USA accrued advantage not by penalizing the Soviet Union directly, but by awarding its own skaters inflated scores. These findings suggest that specific scoring strategies were being used to gain an advantage. Whissell et al. (1993) reported similar findings for the 1984 and 1988 Olympic skating contests, using several criteria to infer bias. National bias was exhibited in awarding significantly more points, maximum scores, higher ranks and more maximum placements to fellow countrymen and women. Such bias was exhibited by all countries' judges with three or more skaters, with fewer instances from countries with less skaters.

In gymnastics, Ansorge and Scheer (1988) addressed the possible use of scoring strategies, because they found not only that judges at the 1984 Olympics scored their own gymnasts higher, but also that they scored immediate competitors lower. Simple sign tests were used to identify bias; although these do not necessarily express magnitude of effect, the imbalance observed is clear. Judges scored their own gymnasts higher than the mean of the other judges 282 times and lower 29 times. More telling was the underscoring of gymnasts in close competition to their own, who were given lower scores than the mean of the other judges on 399 occasions and higher scores on only 190 occasions. This finding certainly suggests a scoring strategy, which increases national advantage.

In recent years, the end of the 'cold war' has reduced political bias to some extent. Nationalistic bias has received vast exposure over the years, most notably in figure skating at the 1978 World Championships, where the USSR judging delegation was suspended by the International Skating Union because of a flagrant display of bias. Because of this, today 'Any judge who places a skater from his own country two spots higher than the panel's average must write a letter of explanation to the referee' (Swift, 1998). Corrective methods may also reduce nationalistic bias. Figure skating, for example, uses a median mark calculated after deletion 
of the highest and lowest marks. In addition, judges are privately informed of the median mark and given the option to change their scoring (International Skating Union, 2000). Such techniques, however, fail to address a more general home advantage. Indeed, if most judges were to score home competitors disproportionately highly, neither elimination of scores nor use of a median mark would affect this, as both techniques simply attempt to reduce the influence of outliers. Home advantage may even be enhanced, as a judge or judges not scoring a home competitor highly would be eliminated by the techniques designed to combat other forms of bias.

The present study focuses on factors that are thought to account for home advantage and to apply to specific Winter Olympic events. Bray and Carron (1993) found home advantage in alpine skiing to be 'moderate'. Several of their performance measures relied simply on comparing home and away competitors, disregarding relative ability. Significantly, when this was addressed (seed vs actual position), they found more evidence of home advantage. The present study addresses the problem by using an intra-nation analysis, comparing the medal successes of each nation when either hosting or not hosting the Olympics (home vs away), thereby avoiding imbalances owing to the relative strength of specific nations.

For two of the 12 disciplines considered (see Table 1), figure skating and freestyle skiing, the outcome is determined entirely by the subjective scores of judges. Ski jumping also features an element of judging (style marks), as does Nordic combined, albeit to a lesser extent. Familiarity with conditions should be most influential in alpine skiing, where variable pistes must be traversed at high speed. In the biathlon and Nordic skiing, conditions may be variable but the lower speeds involved would theoretically marginalize home advantage. Travel factors are relevant in all Olympic events; for any given Olympics, away teams can traverse many time zones $(-17$ to $+16 \mathrm{~h})$.

The aims of the present study were to assess overall home advantage in the Winter Olympics and, more importantly, to determine the influence of factors thought to have a bearing on home advantage. Three factors are considered: subjective officiating, distance travelled and familiarity with local conditions. Greater home advantage is thought to accrue in events with subjective judging than events that rely on objectively measurable performance. Investigation of travel factors is well suited to the changing venues and multi-national nature of the Winter Olympics, as is familiarity with conditions, given the wide variations in, for example, piste as opposed to the far less variable rink size or stadia. We used the Olympics between 1908 and 1998 (see Table 2) to examine these three factors. First, we hypothesized that subjectively judged events display significantly greater home advantage than other events. Secondly, we hypothesized that familiarity with local conditions results in increased home advantage for events where there is most variation in terrain between Olympics (alpine skiing, luge and bobsled). Finally, travel is hypothesized to have a negligible effect.

Table 1. Events used in the analysis (excluding the discontinued skeleton event and events held at only one Olympics)

\begin{tabular}{|c|c|c|c|c|c|}
\hline \multirow[b]{2}{*}{ Event } & \multirow{2}{*}{$\begin{array}{l}\text { No of } \\
\text { hosting } \\
\text { nations }\end{array}$} & \multirow{2}{*}{$\begin{array}{l}\text { Times } \\
\text { held }\end{array}$} & \multirow[b]{2}{*}{ Years } & \multicolumn{2}{|c|}{$\begin{array}{l}\text { No. of medals (points) won } \\
\text { for each event }\end{array}$} \\
\hline & & & & All nations & Host nations \\
\hline 1. Figure skating & 12 & 20 & $1908-98$ & $204(408)$ & $103(192)$ \\
\hline 2. Freestyle skiing & 3 & 3 & $1992-98$ & $30(60)$ & $9(17)$ \\
\hline 3. Ice hockey & 11 & 19 & $1920-98$ & $60(120)$ & $27(56)$ \\
\hline 4. Ski jumping & 10 & 18 & $1924-98$ & 96 (193) & $60(116)$ \\
\hline 5. Nordic combined & 10 & 18 & $1924-98$ & $66(132)$ & $43(92)$ \\
\hline 6. Alpine skiing & 10 & 15 & $1936-98$ & $307(616)$ & $277(565)$ \\
\hline 7. Nordic skiing & 10 & 18 & $1924-98$ & $327(654)$ & $100(200)$ \\
\hline 8. Short track skating & 3 & 3 & $1992-98$ & $48(96)$ & $3(5)$ \\
\hline 9. Bobsled & 10 & 17 & $1924-98$ & $97(194)$ & $74(150)$ \\
\hline 10. Luge (no skeleton) & 7 & 10 & $1964-98$ & 96 (193) & $19(35)$ \\
\hline 11. Biathlon & 7 & 11 & $1960-98$ & $105(210)$ & $19(40)$ \\
\hline 12. Speed skating & 10 & 18 & $1924-98$ & $391(787)$ & $189(383)$ \\
\hline Total & 103 & & & $1827(3663)$ & $923(1851)$ \\
\hline
\end{tabular}


Table 2. Olympic Games by location and host

\begin{tabular}{rrll}
\hline Olympics & Year & \multicolumn{1}{c}{ Location } & $\begin{array}{c}\text { Host } \\
\text { (occasions as host) }\end{array}$ \\
\hline 1 & 1908 & London & United Kingdom (1) \\
2 & 1920 & Antwerp & Belgium (1) \\
3 & 1924 & Chamonix & France (1) \\
4 & 1928 & St. Moritz & Switzerland (1) \\
5 & 1932 & Lake Placid & USA (1) \\
6 & 1936 & Garmisch & Germany (1) \\
& & Partenkirchen & \\
7 & 1948 & St. Moritz & Switzerland (2) \\
8 & 1952 & Oslo & Norway (1) \\
9 & 1956 & Cortina D’Ampezzo & Italy (1) \\
10 & 1960 & Squaw Valley & USA (2) \\
11 & 1964 & Innsbruck & Austria (1) \\
12 & 1968 & Grenoble & France (2) \\
13 & 1972 & Sapporo & Japan (1) \\
14 & 1976 & Innsbruck & Austria (2) \\
15 & 1980 & Lake Placid & USA (3) \\
16 & 1984 & Sarajevo & Yugoslavia (1) \\
17 & 1988 & Calgary & Canada (1) \\
18 & 1992 & Albertville & France (3) \\
19 & 1994 & Lillehammer & Norway (2) \\
20 & 1998 & Nagano & Japan (2) \\
\hline & & &
\end{tabular}

\section{Methods}

The results of the events in the Winter Olympics between 1908 and 1998 were obtained from the Internet (http://www.chu-rouen.fr/jo/johome.html).

\section{Determination of home advantage}

Calculating home advantage in unbalanced competitions has been criticized for not accounting for the relative abilities of home and away competitors (Nevill and Holder, 1999). This imbalance may influence the observed home advantage. The following procedure aimed to address this problem by comparing, for a particular event, the medals or points won by a hosting nation (home) with the medals or points won by the same nation when visiting other Olympic Games (away).

Home advantage for both medals and points was calculated using a four-step procedure, which controlled for nation strength, 'non-hosting' nation performance and number of medals on offer, resulting in unbiased measures of home advantage. Freestyle skiing is used as an example throughout.

Step 1: Eligibility. To allow a fair assessment, a nation's home performances were compared with an aggregate measure of all their away performances. This ensures that a comparatively less successful country, such as
Table 3. Step 1: Medals (points) won by host nations, with non-host nations removed

\begin{tabular}{lllll}
\hline & \multicolumn{4}{c}{ Medals (points*) won } \\
\cline { 2 - 5 } Host nation & France & Norway & Japan & Total \\
\hline France, 1992 & $2(5)$ & $1(1)$ & - & $3(6)$ \\
Norway, 1994 & $1(1)$ & $2(4)$ & - & $3(5)$ \\
Japan, 1998 & $1(2)$ & $1(1)$ & $1(3)$ & $3(6)$ \\
\hline
\end{tabular}

$*$ Gold $=3$ points, silver $=2$ points, bronze $=1$ point.

Yugoslavia, is not unfavourably compared with a more successful country, for example Norway. Clearly, nations who had never hosted the Winter Olympics were eliminated from the analysis, as they had no home performances to compare with their away performances.

For each event, the number of medals and points scored for each hosting country was entered into a table (e.g. see the medals and points scored for freestyle skiing in Table 3). Note that the countries involved varied for each event, since not all events began at the same Olympics. For example, luge began in 1964. This eliminated Switzerland, the hosts in 1928 and 1948, because that country has never hosted luge in its modern form (despite being the home of the 'sliding' sports) and, therefore, had no home performances to compare with their away performances. Similarly, the UK, Belgium, Germany and Italy were eliminated for the same reason, leaving seven eligible nations only from the initial twelve. Similarly, only 10 of the 20 host nations of the Olympic Games were eligible when examining figure skating. Correspondingly, the medals or points won by hosting nations varied (1) with the relative strength of the hosting nations compared to non-hosting nations at each Olympics, and (2) with the total number of medals or points available to all eligible nations (which generally increased over time).

Step 2: Medals on offer and performance of non-hosting nations. Using a simple tally of medals or points as a measure of success would not control for number of medals on offer or for the performance of non-hosting nations. Therefore, each tally and score was divided by the total tally of medals and total score attained by eligible nations at each Olympics. This gives the proportion of medals or points won by each nation of the total medals or points won by all eligible nations at that Olympics (see Table 4). This gave a balanced measure of performance for both medal tally and points for each event, for each country and at each Olympics accounting for both total medals available (to all eligible competitors) and for the performance of non-hosting nations. 
Step 3: Summation of home and away performances. The proportions from the above were summed for each country for home and away Olympics independently. For a particular event, the result was one sum of proportions of medals won at home and one sum of proportions of medals won away, for each eligible nation in each given event, and for all Olympics at which each event was held (see Table 5). The number of home and away Olympics varied both with country and with event. In Nordic skiing, for instance, which began in 1924 (18 Olympics), the USA has been at home three times (away 15 times), Switzerland twice (away 16 times) and Canada once (away 17 times). In luge, however, which began in 1964 (10 Olympics, excluding the now defunct skeleton event), the USA has been at home once (away 9 times), Switzerland never (always away and therefore excluded) and Canada once (away 9 times).

Step 4: Final calculation of home advantage. To obtain fair measures of performance, the home and away sums of proportions for each event were divided by the number of opportunities each hosting country had to score points home and away (each of which is a subset of the Olympics at which each event was held). For biathlon, the home sum of proportions for the USA was divided by 3 and its away sum of proportions by 15; Switzerland's home sum of proportions was divided by 2 and its away sum of proportions by 16; and so on. This took into account nations' failure to win medals at a given Olympics, which would not be the case if simple means were used.

This procedure yielded a mean proportion of medals or points won at home and a mean proportion of medals or points won away for each set of hosting countries for a given event and for all events. Each of these mean proportions can vary between 0 and 1 . A home mean proportion of 1 would indicate that a given country won all medals or points on offer for that event's set of eligible countries when at home. A score of 0.5 would show the country winning a mean of $50 \%$ of the medals or points available to the hosting nations over the set of home Olympics for the given event. Similar logic applies to the away mean proportions.

To obtain a measure of home advantage, the mean away proportion of medals or points was subtracted from the corresponding home proportion of medals or points for each hosting country involved in each event (for all events). This value, home advantage, can vary between -1 (total away advantage) and +1 (total home advantage) with 0 indicating that no advantage

Table 4. Step 2: Medals (points) won divided by the total number available for each host nation

\begin{tabular}{lcccc}
\hline & \multicolumn{3}{c}{ Medals (points*) won divided by totals } \\
\cline { 2 - 5 } Host nation & France & Norway & Japan & Total \\
\hline France, 1992 & $2 / 3=0.67$ & $1 / 3=0.33$ & - & $3(6)$ \\
& $(5 / 6=0.83)$ & $(1 / 6=0.17)$ & $3(5)$ \\
Norway, 1994 & $1 / 3=0.33$ & $2 / 3=0.67$ & & $3(6)$ \\
Japan, 1998 & $(1 / 5=0.2)$ & $(4 / 5=0.8)$ & & \\
& $1 / 3=0.33$ & $1 / 3=0.33$ & $1 / 3=0.33$ & \\
& $(2 / 6=0.33)$ & $(1 / 6=0.17)$ & $(3 / 6=0.5)$ & \\
\hline
\end{tabular}

$*$ Gold $=3$ points, silver $=2$ points, bronze $=1$ point.

Table 5. Step 3: Proportions of medals (points) won by each nation, summed for all home and away Olympics

Medals (points*) won divided by totals

\begin{tabular}{|c|c|c|c|c|c|c|c|}
\hline \multirow[b]{2}{*}{ Host nation } & \multicolumn{2}{|c|}{ France } & \multicolumn{2}{|c|}{ Norway } & \multicolumn{2}{|c|}{ Japan } & \multirow[b]{2}{*}{ Total } \\
\hline & Home & Away & Home & Away & Home & Away & \\
\hline France, 1992 & $0.67(0.83)$ & & & $0.33(0.17)$ & & $0(0)$ & $1(1)$ \\
\hline Norway, 1994 & & $0.33(0.2)$ & $0.67(0.8)$ & & & $0(0)$ & $1(1)$ \\
\hline Japan, 1998 & & $0.33(0.33)$ & & $0.33(0.17)$ & $0.33(0.5)$ & & $1(1)$ \\
\hline
\end{tabular}

\footnotetext{
$*$ Gold $=3$ points, silver $=2$ points, bronze $=1$ point
} 
was accrued as a result of location. Home advantage, therefore, is equal to the mean proportion of medals or points won at home minus the mean proportion of medals or points won away for each nation that had hosted a given event, for all events. For the purpose of analysis, it would be equally legitimate to use differences to compare home and away scores (see Table 6). Table 6 shows that, for freestyle skiing, each event yielded as many pairs of home advantage scores (one for medal tally, one for points scored) as there are hosting countries who have competed in that event.

\section{Determination of travel effects}

As with the determination of home advantage, the numbers of medals or points won by 'hosting' nations are converted to proportions by dividing the total medals or points won by all hosting nations for the given Olympics (see steps 1 and 2 in 'Determination of home advantage'). Rather than summing home and away performances, each away performance must be considered as a separate observation in the analysis, because of the varying travel involved. Travel is expressed as hours of time change (positive-eastward or negative-westward) and determined by time zones traversed from the hosting nation concerned to the relevant Olympic host.

To achieve a fair measure of performance to assess travel factors, the following technique was used. The procedure is identical to that of 'Determination of home advantage' for steps 1 and 2; however, each specific away performance must be considered because of the variation in travel between them. Distance travelled is expressed as the number of time zones crossed, either positively (east) or negatively (west), for each away performance (i.e. the distance from each 'hosting' nation to each Olympic Games). Freestyle skiing is used for illustration (see Tables 7 and 8).

For each hosting country at each away Olympics, a measure of performance is recorded that compares each away score with each hosting country's mean home score, for each specific event. This yields a pair of difference scores (for medals and points) for each country's set of away performances, for all countries and for all events. Each pair of scores also has an accompanying distance measure, expressing the number of time zones traversed and the direction of travel for each of the hosting nations to attend each away Olympics.

By comparing each away performance against mean home performance, weaker hosting nations are not compared unfairly against stronger nations and vice versa, as each performance is set against that country's unique standard measure, home performance. These differences can then be analysed against time zones traversed. It should be noted that this technique excludes comparison of home and away columns of scores, as repetition would create an artificial number of home observations.

\section{Classification of events}

Two separate groupings were used:

(i) Subjectively judged (group 1) and objectively measured (group 2). Group 1 = figure skating and freestyle skiing, Group 2 = all other events.

Table 7. Proportion of medals (points) won in freestyle skiing

\begin{tabular}{lll}
\hline $\begin{array}{l}\text { Competing } \\
\text { nation }\end{array}$ & \multicolumn{1}{c}{ Olympics } & \multicolumn{1}{c}{$\begin{array}{c}\text { Proportion of } \\
\text { host medals } \\
\text { (points) won }\end{array}$} \\
\hline France & Albertville, 1992 & $0.67(0.83)$ \\
France & Lillehammer, 1994 & $0.33(0.2)$ \\
France & Japan, 1998 & $0.33(0.33)$ \\
Norway & Albertville, 1992 & $0.33(0.17)$ \\
Norway & Lillehammer, 1994 & $0.67(0.8)$ \\
Norway & Japan, 1998 & $0.33(0.17)$ \\
Japan & Albertville, 1992 & - \\
Japan & Lillehammer, 1994 & - \\
Japan & Japan, 1998 & $0.33(0.5)$ \\
\hline
\end{tabular}

Table 6. Step 4: Opportunities available to win medals (points) and final calculation of home advantage

\begin{tabular}{|c|c|c|c|c|c|c|}
\hline & \multicolumn{2}{|c|}{ France } & \multicolumn{2}{|c|}{ Norway } & \multicolumn{2}{|c|}{ Japan } \\
\hline & Home & Away & Home & Away & Home & Away \\
\hline Sums of proportions of medals (points) won & $0.67(0.83)$ & $0.67(0.53)$ & $0.67(0.8)$ & $0.67(0.34)$ & $0.33(0.5)$ & $0(0)$ \\
\hline Number of occasions as host & 1 & & 1 & & 1 & \\
\hline Number of occasions away & & 2 & & 2 & & 2 \\
\hline Mean sums of proportions of medals (points) won & $0.67(0.83)$ & $0.33(0.27)$ & $0.67(0.8)$ & $0.33(0.17)$ & $0.33(0.5)$ & $0(0)$ \\
\hline Away mean sums subtracted from home mean sums & \multicolumn{2}{|c|}{$0.67-0.33(0.83-0.27)$} & \multicolumn{2}{|c|}{$0.67-0.33(0.8-0.17)$} & \multicolumn{2}{|c|}{$0.33-0(0.5-0)$} \\
\hline Home advantage & \multicolumn{2}{|c|}{$0.33(0.57)$} & \multicolumn{2}{|c|}{$0.33(0.63)$} & \multicolumn{2}{|c|}{$0.33(0.5)$} \\
\hline
\end{tabular}


Table 8. Differences in proportions of medals (points) won and time zones traversed: Freestyle skiing

\begin{tabular}{|c|c|c|c|c|}
\hline $\begin{array}{l}\text { Competing } \\
\text { nation }\end{array}$ & $\begin{array}{c}\text { Proportion } \\
\text { of host } \\
\text { medals } \\
\text { (points) } \\
\text { won at } \\
\text { home }\end{array}$ & $\begin{array}{c}\text { Proportion } \\
\text { of host } \\
\text { medals } \\
\text { (points) } \\
\text { won at each } \\
\text { away Olympics }\end{array}$ & $\begin{array}{l}\text { Differences in } \\
\text { proportions } \\
\text { (response } \\
\text { variable) }\end{array}$ & $\begin{array}{c}\text { Time-zone } \\
\text { change } \\
\text { (h) }\end{array}$ \\
\hline France & $0.67(0.83)$ & 0.33 (0.2) Norway, 1994 & $0.34(0.63)$ & 0 \\
\hline France & $0.67(0.83)$ & 0.33 (0.33) Japan, 1998 & $0.34(0.5)$ & +8 \\
\hline Norway & $0.67(0.8)$ & $0.33(0.17)$ France, 1992 & $0.33(0.63)$ & 0 \\
\hline Norway & $0.67(0.8)$ & 0.33 (0.17) Japan, 1998 & $0.33(0.63)$ & +8 \\
\hline Japan & $0.33(0.5)$ & $0(0) \quad$ France, 1992 & $0.33(0.5)$ & -8 \\
\hline Japan & $0.33(0.5)$ & Norway, 1994 & $0.33(0.5)$ & -8 \\
\hline
\end{tabular}

(ii) Subjectively judged (group 1), familiarity (group 2) and other events (group 3). Group 2 = alpine skiing, luge and bobsled.

The subjectively judged group comprised events where the outcome measure is entirely made up of judges' scores. In the familiarity group, we included alpine skiing, luge and bobsled, since we felt they experience the greatest variation in conditions. Given this reasoning, sports using ice rinks were removed, as there are only minimal differences in the ice conditions of stadia compared with the wide variation in mountains between Olympics. Similarly, ski jump and Nordic combined were excluded owing to a lack of sufficient variation, as were Nordic skiing and biathlon because of the low speeds involved, allowing adaptation to terrain. For luge and bobsled, we acknowledge that tracks are often constructed over relatively short times before competition. Because we lacked information on track construction, we included luge and bobsled in the familiarity group because of their highly variable terrain and high speeds.

\section{Statistical methods}

Preliminary analysis of the home advantage response variables indicated that the residuals were not normally distributed; for this reason, non-parametric statistics were used throughout. In the first instance, this involved a Wilcoxon signed-rank test to determine overall home advantage. Then, a series of Kruskal-Wallis tests were used to examine the factors of subjective officiating and familiarity with local conditions. Finally, regression analysis was used to assess the influence of travel on performance, fitting linear, quadratic and exponential terms. The number of observations used for figures and analyses (excluding travel) can be determined by the addition of relevant events in the 'No. of hosting nations column' of Table 1. All error bars on figures denote the standard error.

\section{Results}

\section{Overall home advantage}

Measures of performance for medals and points were calculated home and away (Table 6). The difference between home and away scores was calculated for each hosting nation and for all events to give an overall measure of home advantage (Fig. 1). Using a simple Wilcoxon signed-rank test on two sets of 103 observations, home advantage was found to be significantly greater than zero for both medals $(P=0.029)$ and points $(P=0.023)$.

\section{Subjective judgements and variable local conditions}

Initially, two Kruskal-Wallis tests were used to determine differences in home advantage between events (see Fig. 2). No significant differences were found either for points $\left(H_{11}=17, P=0.093\right)$ or medals $\left(H_{11}=15.17\right.$, $P=0.177)$.

Kruskal-Wallis tests were used to establish whether home advantage differed in events where there was subjective judging. Significantly greater home advantage was found for group 1 versus group 2 (grouping i) for both medals $\left(H_{1}=4.35, P=0.037\right)$ and points $\left(H_{1}=4.13, P=0.042\right)$ (see Fig. 3). Grouping (ii) also showed significant differences in home advantage between groups for medals $\left(H_{2}=6.19, P=0.046\right)$ and points $\left(H_{2}=6.25, P=0.044\right)$ (see Fig. 4$)$. Subsequent post-hoc tests (though not strictly legitimate given the lack of normality) demonstrated that the significant findings observed were the result of differences between groups 1 (subjectively judged) and 3 (other events). 


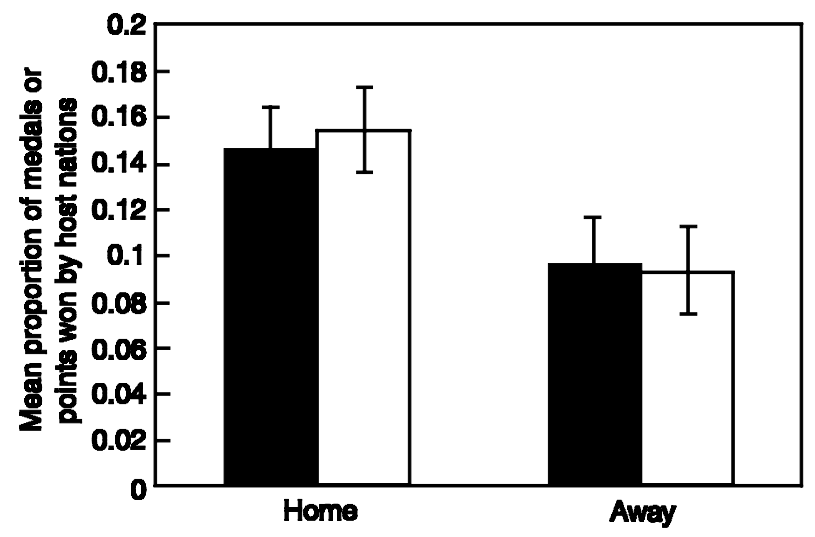

Fig. 1. Proportions of medals $(\square)$ and points $(\square)$ won home and away by host nations, for all nations, Olympics and events.

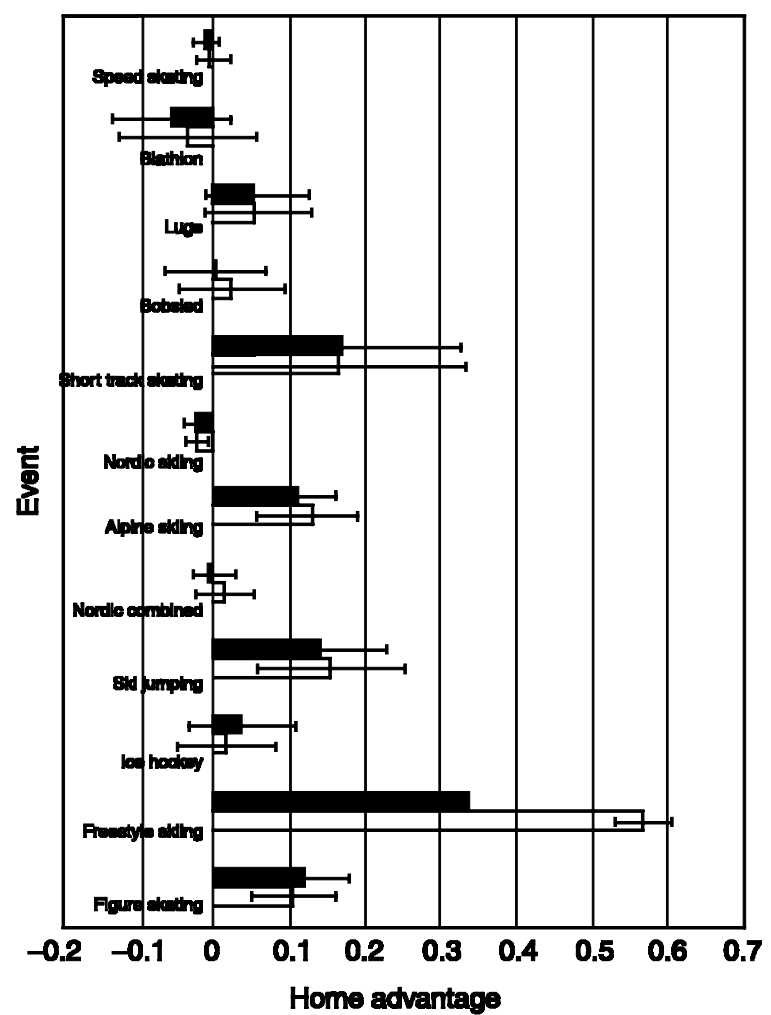

Fig. 2. Mean home advantage measures for all events by medals ( $\square$ ) and points $(\square)$.

Further Kruskal-Wallis tests revealed no significant differences between all nations' home advantage for medals $\left(H_{\text {adj }}=11.0\right.$ with 11 degrees of freedom, $P=$ $0.448)$ or points $\left(H_{\mathrm{adj}}=11.1, P=0.439\right)$. Similarly, there were no significant fluctuations in home advantage over time for medals $\left(H_{\mathrm{adj}}=14.0\right.$ with 19 degrees of freedom, $P=0.786)$ or points $\left(H_{\mathrm{adj}}=12.2, P=0.874\right)$.

\section{Travel factors}

To determine travel effects, distance travelled for away

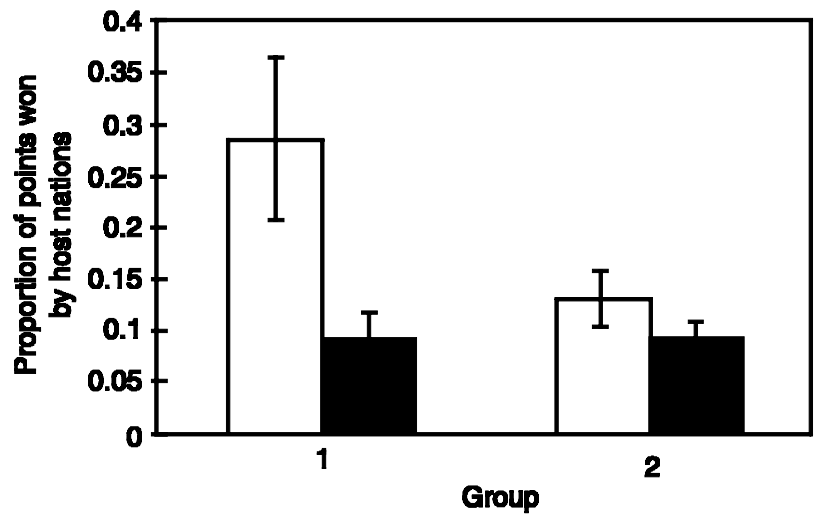

Fig. 3. Home $(\square)$ and away ( $\square$ ) point winning performances for two groups: (1) subjectively and (2) non-subjectively judged.

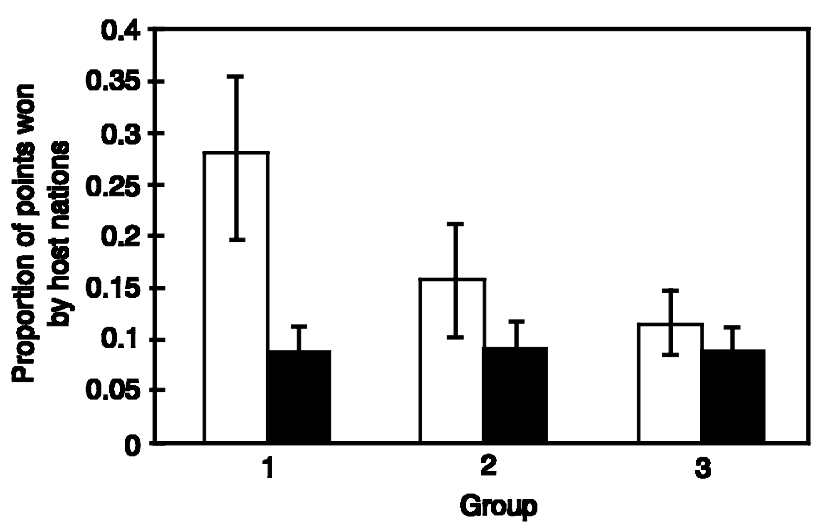

Fig. 4. Home $(\square)$ and away ( $\square$ ) point winning performances for three groups: (1) subjectively judged, (2) variable local conditions and (3) non-subjectively judged.

performances was recorded for each hosting nation, event and Olympics. These were subtracted from each hosting nation's mean home score for each given event, for both medals and points. This process is comprehensively described below; for simplicity, however, these units of observation will be collectively referred to as either medal-winning or point-winning performances.

Initially, differences between medal- and pointwinning performances were determined with time zones traversed as a factor (20 levels, between -17 and $+16 \mathrm{~h}$ ). Two Kruskal-Wallis tests showed highly significant differences between time zones crossed for both medals $\left(H_{\text {adj }}=83.5\right.$ with 19 degrees of freedom, $P<0.001)$ and points $\left(H_{\text {adj }}=76.8, P<0.001\right)$. This result, however, could simply be a reflection of specific countries performing particularly well or badly at a given location or Olympics, and does not necessarily indicate trends in performance over hours travelled. To this end, regression analysis was used for both medaland point-winning performances (see Fig. 5), fitting linear 'time zones crossed', quadratic '(time zones 


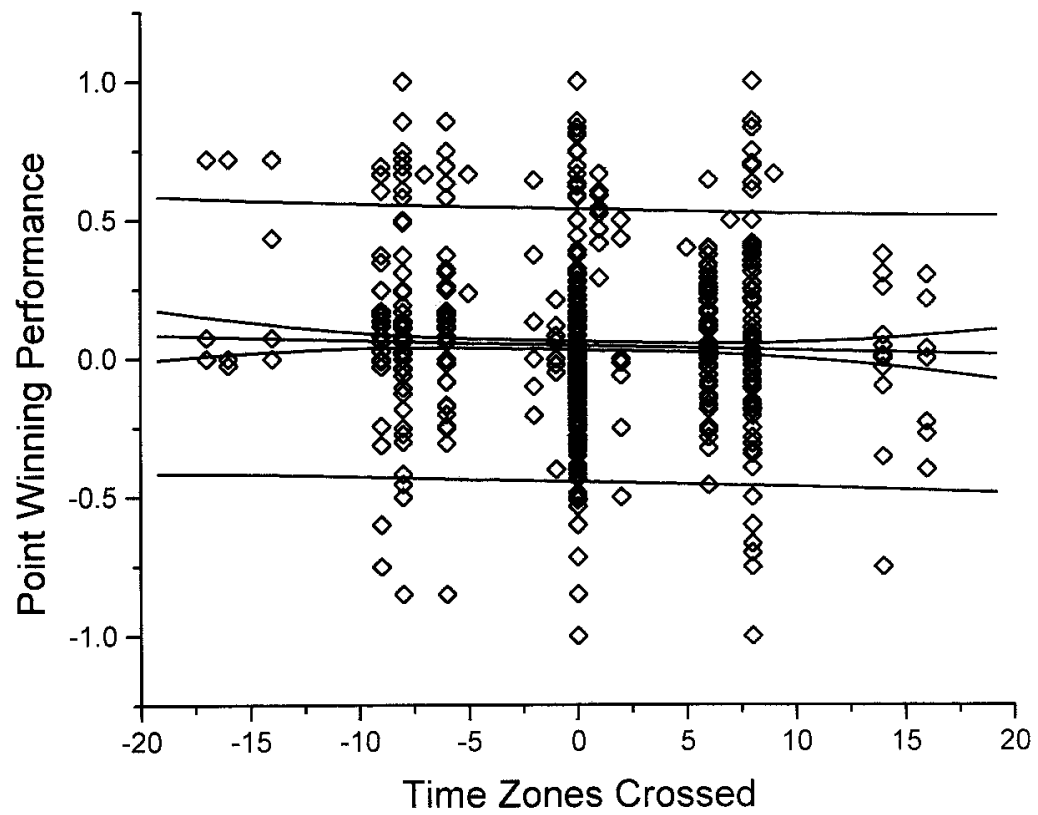

Fig. 5. Point winning performance plotted against distance travelled for all events, nations and Olympics, with $95 \%$ confidence and prediction intervals.

crossed)' and exponential 'exp(time zones crossed)' terms as predictors. This allowed us to examine the possibility that performance increased or decreased from -17 to $+16 \mathrm{~h}$ crossed (linear) and that performance became worse with increasing hours crossed, east and west (quadratic). Alternatively, east or west travel had an influence on performance alone (exponential).

None of these predictors was found to be significant for either medal- or point-winning performance $(P>$ 0.05); fitting all terms simultaneously was only able to explain a negligible amount of the variance $\left(R^{2}=0.3 \%\right)$. Only the constant term was found to be significant (constant $\approx 0.045, P<0.001$ in all cases), identifying a consistent home advantage throughout. There were no significant changes in the travel effect over time. Grouping Olympics by date (1908-24, 1928-36, 194856, 1960-68, 1972-80, 1984-92, 1994-98), and again fitting all three terms simultaneously for each period, explained only a very small portion of the variance $\left(R^{2}=0.4 \%\right)$. This demonstrated that time period had only a small influence on the travel effect.

\section{Discussion}

Based on data from all Winter Olympics, significant evidence of home advantage was identified; this was expected given the wealth of support for the home advantage phenomenon. Of greater interest was whether specific differences in home advantage would emerge between groups of events. Although no sig- nificant differences were found across all events (Fig. 2), when the two separate groupings of events were analysed, some interesting differences in home advantage emerged. Grouping events based on whether they were subjectively judged or not demonstrated that subjective judgements as a form of assessment produced significantly greater home advantage than events with objectively measurable performance or outcome (e.g. time, goals or distance). This finding may reflect the better performances of athletes competing in front of a supportive partisan audience. However, this would result in consistently elevated home advantage over all events, whenever crowds were present. An alternative explanation is that the judges responded more positively to crowd noise when judging home competitors' performances. This conclusion is speculative, since the use of such archival data does not permit an examination of the make-up of specific crowds. Nevertheless, this rationale is plausible considering previous research has reported that officials consistently make more subjective decisions in favour of the home team (Lefebrve and Passer, 1974; Varca, 1980; Summer and Mobley, 1981; Greer, 1983; Lehman and Reifman, 1987; Glamser, 1990). Subsequent research has highlighted the role of the crowd in this process (Nevill et al., 1996, 1999).

It would appear that subjective assessment by officials can explain a large proportion of the variation in observed home advantage in Winter Olympic events, especially given that these events appear to have no other discernible and exclusive factors influencing home 
advantage. Figures 3 and 4 also show that the variation in home advantage between groups of events was a reflection of differences in home rather than away performances. Away performance remains fairly constant throughout, suggesting the imbalance is a direct result of enhanced home and not deteriorating away performance.

Familiarity with local conditions (grouping ii) was shown to have an intermediate influence on home advantage between the subjectively judged group and the remaining events (grouping iii). The significant differences between the three groups, however, were a reflection of differences between the 'subjectively judged' group and 'other events', although familiarity was shown to have some influence. This finding should be treated with caution given the difficulty of assessing when familiarity with local conditions is most influential (to assemble a familiarity group). Although events where most variation was possible were chosen, we recognize that no discrete grouping would be perfect when dealing with a variable that is difficult to assess objectively. Familiarity with local conditions remains, as Courneya and Carron (1992) suggested, both an under-investigated and elusive possible source of home advantage. The results of the present study add to a growing list of inconclusive or contradictory findings regarding such a familiarity concept (e.g. Dowie, 1982; Pollard, 1986; Barnett and Hilditch, 1993; Clark and Norman, 1995).

For travel, no appreciable trends were noted, regardless of the regression model fitted. The only significant term in the regression analysis (the constant) simply identified consistent home advantage, regardless of time zones traversed in any given away performance. This suggests that the absolute extent or direction of travel had a negligible influence, with a maximum of only $0.3 \%$ of the variance being explained. Perhaps of greater importance is the fact that travel had taken place, as shown by the general home advantage found for all events, and the significant constant in all regressions. However, this should not give the impression that jet-lag is illusory, as it is probable that Olympic athletes arrive in good time to allow adjustment of their body clocks. In contrast, athletes in studies reporting impaired performance with time zones crossed (e.g. Jehue et al., 1993; Waterhouse et al., 1997) generally did not arrive in good time. In future competition, precise data concerning time of arrival and competition would allow a more thorough assessment of the influence of travel, although the archives did not contain such detailed information.

The volume of data, number of hosts and number of events falling into particular categorizations were limitations of the Winter Olympic data. To overcome these, future research should apply similar methods to the more substantial data set provided by the Summer Olympics. Without mountainous terrain as a requirement for a host, this gives a larger set of 17 hosting nations over 24 Olympics (including Sydney 2000). Also, the larger range of events would allow more thorough investigation into each of the factors that influence home advantage. A subjectively judged group, for instance, could contain aquatics, gymnastics and diving, as well as possibly judo and wrestling. Gymnastics alone has awarded 775 medals, excluding Sydney 2000, 541 more than the subjectively judged group for the Winter Olympics, giving some measure of the size of the data set.

In summary, events in the Winter Olympics relying on subjective assessment by judges yielded significantly greater home advantage than other events, an imbalance that appeared to be independent of corrective methods designed to eliminate nationalistic and political bias. Our findings may reflect the way judges respond to the reactions of the crowd when judging home competitors' performances, which is reasonable based on the results of previous research. Familiarity with local conditions was shown to have a limited effect, while degree and direction of travel were shown to produce no discernible trends or differences in performance.

\section{References}

Ansorge, C.J. and Scheer, J.K. (1988). International bias detected in judging gymnastic competition at the 1984 Olympic games. Research Quarterly for Exercise and Sport, 59, 103-107.

Barnett, V. and Hilditch, S. (1993). The effect of an artificial pitch surface on home team performance in football (soccer). Fournal of the Royal Statistical Society, 156, 39-50.

Bray, S.R. and Carron, A.V. (1993). The home advantage in alpine skiing. Australian fournal of Science and Medicine in Sport, 25, 76-81.

Clark, S.R. and Norman, J.M. (1995). Home ground advantage of individual clubs in English soccer. The Statistician, 44, 509-521.

Courneya, K.S. and Carron, A.V. (1992). The home advantage in sport competitions: A literature review. Fournal of Sport and Exercise Psychology, 14, 13-27.

Dowie, J. (1982). Why Spain should win the world cup. New Scientist, 94, 693-695.

Glamser, F.D. (1990). Contest location, player misconduct, and race: A case from English soccer. Fournal of Sports Behaviour, 13, 41-49.

Greer, D.L. (1983). Spectator booing and the home advantage: A study of social influence in the basketball arena. Social Psychology Quarterly, 46, 252-261.

International Skating Union (2000). Special Regulations Figure Skating 2000. Quebec: International Skating Union.

Jehue, R., Street, D. and Huizenga, R. (1993). Effect of time-zone and game time changes on team performance: 
National Football League. Medicine and Science in Sports and Exercise, 25, 127-131.

Lefebvre, L.M. and Passer, M.W. (1974). The effects of game location and importance on aggression in team sport. International Fournal of Sport Psychology, 5, 102-1 10.

Lehman, D.R. and Reifman, A. (1987). Spectator influence on basketball officiating. Fournal of Social Psychology, 127, 673-675.

Nevill, A.M. and Holder, R.L. (1999). Home advantage in sport: An overview of studies on the advantage of playing at home. Sports Medicine, 28, 221-236.

Nevill, A.M., Newell, S.M. and Gale, S. (1996). Factors associated with home advantage in English and Scottish soccer. Fournal of Sports Sciences, 14, 181-186.

Nevill, A.M., Balmer, N.J. and Williams, A.M. (1999). Crowd influence on decisions in association football. Lancet, 353, 1416.

Pace, A. and Carron, A.V. (1992). Travel and the home advantage. Canadian fournal of Sports Science, 17, 60-64.
Pollard, R. (1986). Home advantage in soccer: A retrospective analysis. Fournal of Sports Sciences, 4, 237-248.

Schwartz, B. and Barsky, S.F. (1977). The home advantage. Social Forces, 55, 641-661.

Seltzer, R. and Glass, W. (1991). International politics and judging in Olympic skating events: 1968-1988. Fournal of Sport Behavior, 14, 189-200.

Sumner, J. and Mobley, M. (1981). Are cricket umpires biased? New Scientist, 91, 29-31.

Swift, E.M. (1998). Blind justice. Sports Illustrated, 88, 53-50.

Varca, P. (1980). An analysis of home and away game performance of male college basketball teams. Fournal of Sport Psychology, 2, 245-257.

Waterhouse, J., Reilly, T. and Atkinson, G. (1997). Jet-lag. Lancet, 350, 1611-1616.

Whissell, R., Lyons, S., Wilkinson, D. and Whissell, C. (1993). National bias in judgements of Olympic-level skating. Perceptual and Motor Skills, 77, 355-358. 